\title{
Polymeric Nano-half-shells Prepared by Simple Solvent Evaporation Method
}

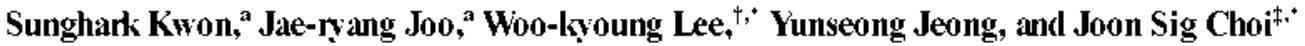 \\ School of Chemistry \& Molecular Engineering, Seoul National Cniversin. Seoul 151-7+2, Korea \\ tSchool of Nano-engineering, Inje Lniversitv, Gimhae, Gumgnam 621-749, Korea. "E-mail: wlee Ginje.ackr \\ -Department of Biochemistry, College of Vatural Sciences, Chungnam National Vniversity. Daejeon $305-764$. Korea \\ E-mail: joonsigácnuack $r$ \\ Received November 3, 2008, Accepted November 11, 2008
}

Key Wonds: Nano-half-shells. Poloxamer, PLGA, Solvent evaporation method

Nano- and microparticles composed of degradable polymers have been used for drug and gene delivery system ${ }^{1.7}$ Recently, polymeric hollow microspheres were developed for pulmonary delivery of drugs and genes. ${ }^{8.9}$ In general, an oil-in-water (o/w) emulsion solvent evaporation method has been used for the preparation of poly (D.L-lactide-co-glycolic acid) (PLGA) nano- and microparticles which had spherical shapes. ${ }^{16.13}$ although hollow microspheres can be prepared by other methods such as water-in-oil-in-water $(w / O / w)$ double emulsion solvent evaporation ${ }^{9.13-14}$ and jet spraying with a nozzle. ${ }^{8.15}$ In this article, we report that nano-half-shells could be prepared by the same oil-in-water emulsion solvent evaporation method by adding Pluronic ${ }^{\mathrm{k}} \mathrm{F} 127$ (poloxamer) to the organic phase. Generally, half-shells are not thought to be produced spontaneously due to their high surface tension. Thus poloxamer seems to play a key role in generating the thermody namically unfasorable stnicture of nano-half-shells.

When PLGA nanoparticles prepared in an organic phase containing PLGA and poloxamer were subject to morphological analysis by scanuing electron microscopy, half-shell structures were hardly observed in PLGA nanoparticles with less than $2.5 \%$ poloxamer. whereas $2.5 \%$ poloxamer-fonmulated PLGA nanoparticles mostly constructed nino-half-shells which were bigger than other spherical nanoparticles (Figure 1). Thus. we think that the poloxamer dissolved in the organic phase seems to be an important factor in generating such half-shell type PLGA nanoparticles.

Figure 2 shows the content of poloxamer in PLGA nano- particles. The poloxamer content increased with the amount of poloxamer used in the preparation of poloxamer-formulated PLGA nanoparticles. Since the nano-half-shells exhibited a high content of poloxamer. the result suggested that nanohalf-shells were not generated by the removal of poloxamer during preparation. On the contrary, the structures of nanohalf-shells were thought to be closely related with the high incorporation efficiency of poloxamer. which was conpared by calculating the integral value ratios of ${ }^{l} H$ NMR data for the poloxamer-formulated PLGA nanoparticles to the respective standard $\mathrm{CDCl}_{3}$ solutions prepared by just dissolving each polymer together at the same concentration. Figure 3 showed that the incorporation efficiency increased in the range of 0.5 to $2.0 \%$ and thereafter remained over $50 \%$ in the range of 2.5 to $5.0 \%$ poloxamer-formulated PLGA nanoparticles. Thus. the incorporation efficiency of poloxamer is considered to be a key factor for the constnuction of the nano-half-shell structure

The trials using other polymers at the same preparation condition were attented to verify this assuntion that the formation of nano-half-shells is dependent upon the poloxamer incorporation efficiency. As shown in Figure 3, other polymers exhibited low incorporation efficiencies of poloxamer (below $5 \%$ ), and only nanometer size spherical structures were observed. Moreover. the organic phase containing various ranges of polyethylene glycol $(0.0 .5 .1 .0,1.5 .2 .0$ and $2.5 \%$ : $\mathrm{w} / \mathrm{v}$ ) and $5 \%$ PLGA could not generate such nano-half-shell structures. Thus, the unique properties of PLGA and poloxamer
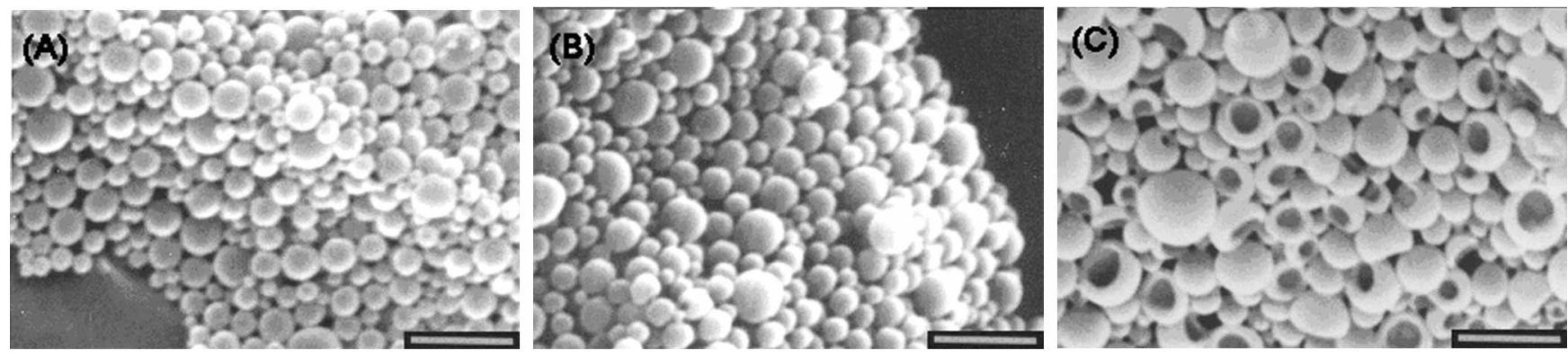

Figure 1. Morphological analysis of PLGA nanoparticles by scanning electron microscopy, (A) $0 \%$, (B) $0.5 \%$, (C) $2.5 \%$ poloxamer-tomulated respectively. The bars indicate $1 \mu \mathrm{m}$.

"I he first two authors contributed eyually to this work. 


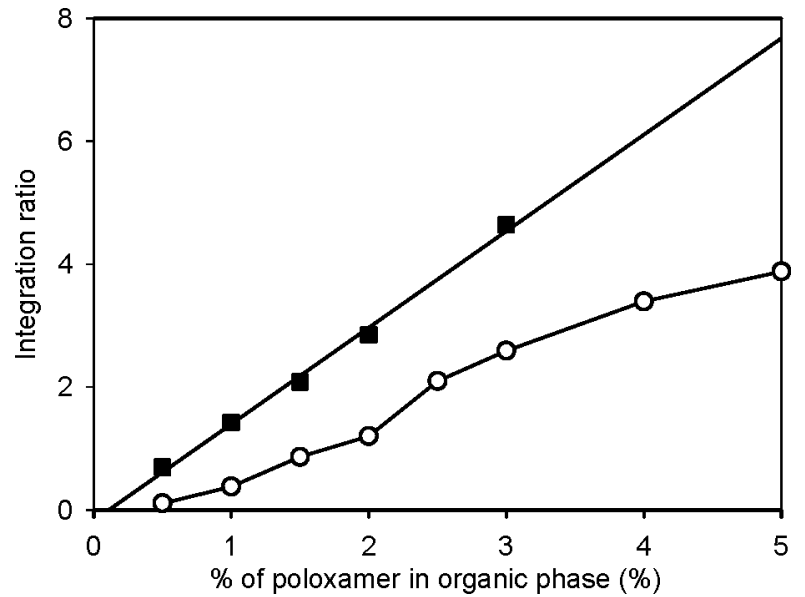

Figure 2. Integration ratios of the poloxamer peak and the PLGA peak in ${ }^{1} \mathrm{H} N \mathrm{NR}$ spectra, ( $)$ the standard solutions $\left(\mathrm{CDCl}_{3}\right.$ ) dissolving poloxamer and PLGA as preparation solutions, $(O)$ the range of $0 \%$ to $5.0 \%$ poloxamer-formulated PLGA nanoparticles.

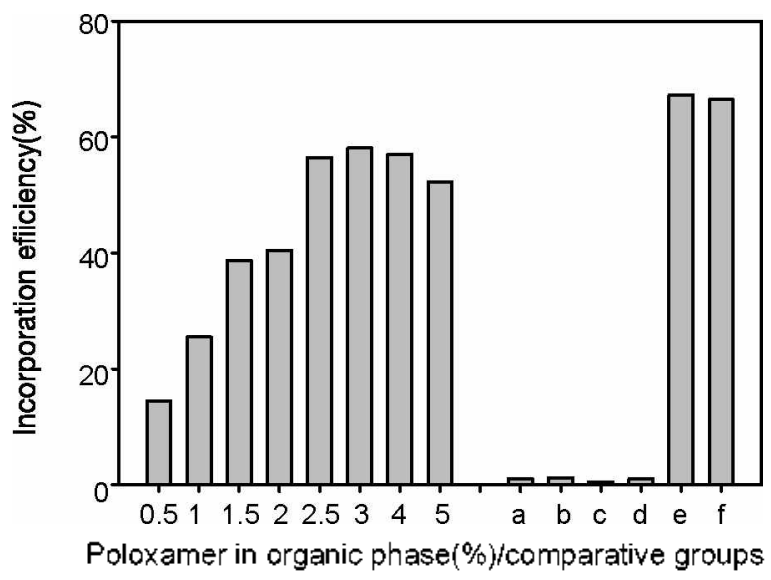

Figure 3. Incorporation efficiencies of poloxamer in the range of $0.5 \%$ to $5.0 \%$ poloxamer-formulated PLGA nanoparticles and those of comparative groups, (a) higher molecular weight PLGA, (b) PLGA $(85: 15$ ). (c) poly lactide, and (d) polystyrene, (e) $0 \%$ polosamer-tormulated PLGA nanoparticles prepared using the outer water phase containing $2.5 \%(\mathrm{w} / \mathrm{v})$ poloxamer, (f) $2.5 \%$ poloxamer-formulated PLGA nanoparticles prepared using the outer water phase containing $2.5 \%(\mathrm{w} / \mathrm{v})$ polosamer.

seem to be the crucial factors in elucidating the mechanism of nano-half-shell fornation. Since the molecular weight of PLGA itself was small ( $\mathrm{Mw}$ 28.032), it is relatively more hydrophilic than other polymers used in this experiment. In addition, although both polyethylene glycol and polosamer can be dissolved in water and methy lene chloride. poloxamer is known to be a surfactant and holds an amphiphilic property showing temperature-dependent rheological properties in aqueous solution because it has another hydrophobic polypropylene oxide block compared with polyethylene glycol. ${ }^{16,1 ?}$

Thus. one of the unique properties of the organic phase containing PLGA and poloxamer could be its water-trapping ability. Poloxamer is thought to be diffised to the outer water phase during emulsification after trapping water into the organic phase on account of its ampliphilic nature. Moreover. the hyddrophilic property of PLGA might enhance the water-trapping efficiency in the organic phase. which seems
(A)

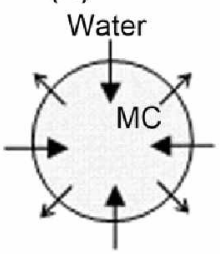

(D)

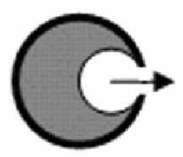

(B)

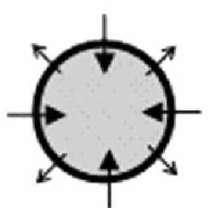

(E)

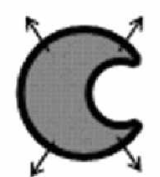

(C)

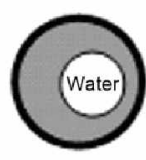

(F)

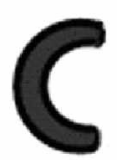

Scheme 1. The postulated mechanism for the formation of nanohalf-shells.

to cause fast solidification at the surface and the creation of the hollow structure. This suggestion of fast solidification could also explain the higher incorporation ratio of poloxamer and the bigger size in nano-half-shells. Thus. nano-half-shells were thought to be generated during the solidification stage.

The suggested mechanism for nano-half-shell formation may be explained as follows. and is presented in Scheme 1. Initially, water is diffused into the organic phase and metlylene chloride evaporates as soon as the emulsion is created (A). At the same time the surface of the emulsion solidifies quickly depending on the water entrapping ability of the organic phase (B). which corresponds to a rapid solvent removal phase in the literature. ${ }^{18}$ In this stage. since methylene chloride can be evaporated and water can be diffused into the inner phase through the thin solidified film. the empty space left by methylene cluoride evaporation is replaced by water until the point at which the two phases are separated and an inner water emulsion is created $(\mathrm{C})$. This structure is basically the same as the structure of the water-in-oil-in-water double emulsion method. At this stage. similar to a solvent removal phase. a viscous layer of polymer and water emulsion can be stabilized by the surfactant effect of poloxamer. which seems to be allocated at a defined ratio between water and methylene chloride. This suggestion also explains why all nano-half-shells show similar incorporation efficiencies over $50 \%$. Then. if this inner water is in contact with any part of the emulsion surface. water may move to the outer aqueous phase forming a hole of which the size depends on the amounts of the entrapped water (D). Then. the inner surface of the organic polymer layer would also solidify. and the remaining methy lene chloride would evaporate through both the outer and inner surface (E). and finally nano-half-shells are generated (F).

Since these processes. after water uptake, corresponded with the suggestions in the literature. ${ }^{1+}$ the poloxamer was considered to produce the porous hollow microspheres if a mild emulsifying method such as stirring was used instead of an ultrasonic processor. Actually, the porous hollow microspheres could be prepared by adding $2.5 \%$ (w/v) poloxamer to the organic phase of $5 \%(w / \mathrm{w})$ PLGA with stirring (data not shown). 
In conclusion. PLGA nano-half-shells were prepared by the oil-in-water emulsion solvent evaporation method. It is suggested that the structure results from the sequential events including fast solidification. phase separation and water escape. Since these nano-half-shells are nanostnictures with low densities. they may have the possibility of being used as carriers for pulmonary drug delivery sy stem.

\section{Experimental Section}

Nanoparticle Preparation PLGA nanoparticles were prepared with an organic phase of methylene clloride containing various amounts of poloxamer (0.0.5. 1.0. 1.5, 2.0 and 2.5\%; w/v) respectively with 5\% (w/v) PLGA (50:50. Mw 28.032) to verify whether poloxamer could affect the nanostructures. The oil-in-water emulsion was produced by using an ultrasonic processor to emulsify $4 \mathrm{~mL}$ of methylene chloride solution into $40 \mathrm{~mL}$ of $1 \%(w / \mathrm{s})$ polyvinyl alcohol (Mw 30,000 70.000) aqueous solution and then stirred for 12-18 hours at room temperature to evaporate methylene chloride. After evaporation. the solidified PLGA nanoparticles were washed twice with distilled water by centrifugation at $20.000 \mathrm{rpm}$ for 10 minutes, and lyophilized.

Other polymers. such as higher molecular weight PLGA (50:50. Mw 40,000 75,000), PLGA (85:15. Mw 50,000 75,000 ). poly lactide (Mw 85.000 160.000), and poly sty rene $(\mathrm{Mw} 350.000)$, were dissolved in methylene chloride $(5 \%$ w/v) respectively with $2.5 \%(w / v)$ poloxamer and applied to the same protocol of PLGA nanoparticle preparation.

Scanning Electoon Microscopy. The shape and morphological examinations of polymer nanoparticles were performed by scanning electron microscope (JSM 840-A. Jeol Ltd, Tokyo, Japan). Nanoparticles were re-suspended in distilled water. 15 $\mu \mathrm{L}$ drops placed on a slide glass $(35 \times 25 \mathrm{~mm})$ and dried at room temperature under reduced pressure to get a uniform layer of particles. The samples were coated with platinum using a sputter coater (Cressington 108, Jeol Ltd, Tokyo. Japan).

Measuring Poloxamer Content by ${ }^{1}$ H NMR. To investigate the mechanism of nano-half-shells formation. the amounts of poloxamer remained in PLGA nanoparticles were measured by ${ }^{\text {H }}$ NMR spectroscopy. Three major peaks of PLGA and one major peak of poloxamer were found in the ${ }^{1} \mathrm{H}$ NMR spectra of PLGA nanoparticles dissolved in $\mathrm{CDCl}_{3}$. The ratio of integration values was calculated as a parameter for the content of poloxamer in PLGA nanoparticles.

Aclanowledgments. J. S. Choi specially thanks Prof. Jong Sang Park at School of Chemistry. Seoul National University for his valuable support and discussion.

\section{Refeiences}

1. Choi, J. S.; Choi, Y. H.; Park, T. Bull. Korean Chem. Soc. 2004, 25,1025 .

2. Choi, J. S.: Lee, E. J.: Park, S.: Kim, H.; Park, J. S. Bull. Korean Chent. Soc. 2001, 22, 261

3. Kim, T.: Seo, H. J.: Choi, J. S.: Jang, H. S.; Baek, I.; Kim, K.; Park, J. Biontacrontolecules 2004, 5, 2487

4. Kim, T.; Bai, C. Z; Park, I. Bull. Korean Chem. Soc. 2007, 28 , 1317.

5. Kim, T.; Baek, T.; Bai, C. Z.; Park, T. Biontaterials 2007, 28, 2061

6. Lim, Y.; Kim, T; Lee, J. W.; Kim, S.; Kim, H.; Kim, K ; Park, J. Biocomingate Chem. 2002,13.1181

7. Lim, Y; Kim, S.; Suh. H.; Park, I. Bioconjugate Chem. 2002, 13, 952.

8. Anold, M. M.: Gorman, E. M.: Schieber, L. I. J. Control. Release 2007,121, 100.

9. Mohamed, F.; van der Walle, C. F. Int. J. Pham 2006, 311, 97.

10. Lim, H. J.: Nam, H. Y.: Lee, B. H.; Kim, D. J.: Ko, J. Y.; Park, J. Biotechrol. Prog. 2007, 23, 693.

11. Nam, S. H.: Nam, H. Y.: Too, I. R.; Baek, I. S.: Park, J. Bull. Korean Chent. Soc. 2007, 28, 397.

12. Lee, W.; Park, J.; Yang, E. H.; Suh, H.; Kim, S. H.; Chung, D. S.; Choi, K.: Yang. C. W, Park, T. J. Control Release 2002, 84 , 115.

13. Lee, W.; Park, I.: Jung, S.: Yang. C. W.: Kim, W.: Kim, H.: Park, J.; Park J. J. Control. Release 2005, 105,77.

14. Yang, Y. Y.; Shi, M.; Goh, S. H.; Moochhala, S. M.; Ng, S.; Heller, T. J. Control. Release 2003, 88, 201

15. Bölumer, M. R.; Schroeders, R.; Steenbakkers, J. A. M: de Winter, S. H. P. M.: Duineveld, P. A.: Lub, J.: Nijssen, W. P. M.: Pikkemaat, J. A.; Stapert, H. R. Colloids and Surfaces A: Phisicochen. Eng. Aspects 2006, 289, 96.

16. Wang. P. L.: Jolnston, T. P. J. Parenter. Sci. Technol. 1993, 47 , 183

17. Bohorquez, M.; Koch, C.; Trygstad, T.; Pandit, N. J. Colloid Interface Sci. 1999, 216, 34

18. Crotts, G.; Park, T. G. J. Control Release 1995, 35, 91. 